\title{
Inclusão social para pessoas com Síndrome de Down: Análise de uma visita guiada pelo Congresso Nacional (Brasília, Brasil)
}

\author{
Social inclusion for people with Down Syndrome: analysis of a tour by the National \\ Congress (Brasília, Brazil)
}

\author{
Carolina Augusti (AUGUSTI, C.) ${ }^{*} \mathrm{e}$ \\ Luiz Daniel Muniz Junqueira (JUNQUEIRA, L. D. M.) ${ }^{* *}$
}

RESUMO - Realizou-se esse estudo com a intenção de identificar a contribuição de um passeio de lazer, e por vezes turístico, no desenvolvimento intelectual e social de pessoas com síndrome de Down, considerando suas características físicas e psicológicas. A pesquisa teve abordagem qualitativa com técnicas bibliográfica, documental e de levantamento, sendo realizada durante uma visita guiada em maio de 2012 no Congresso Nacional (Brasília, Brasil) por meio de entrevistas semiestruturadas aplicadas aos pais e responsáveis e às pessoas com síndrome de Down. Entrevistou-se, ainda, o coordenador de Educação Inclusiva do Distrito Federal para compreender as políticas de inclusão desse grupo social. Na pesquisa se observou o comportamento dos jovens com síndrome de Down durante a visita guiada no Congresso Nacional. Como resultado, foi possível verificar que as atividades de lazer e turísticas podem ser ferramentas no desenvolvimento educacional e fator de maior inclusão social.

Palavras-chave: Turismo; Lazer; Síndrome de Down; Inclusão social; Visita guiada; Congresso Nacional.

ABSTRACT - This study was carried out with the intention of identifying the contribution of a leisure ride, and touristic sometimes, in the intellectual and social development of people with Down syndrome, considering their physical and psychological characteristics. The survey had a qualitative approach with bibliographical, documentary and survey technical, being conducted during a tour in may 2012 in National Congress (Brasilia, Brazil) by means of semi-structured interviews applied to the parents and guardians and in people with Down syndrome. Interviewed, yet, the Coordinator of inclusive education of the Distrito Federal to understand inclusion policies of this social group. The research noted the behavior of young people with Down syndrome during the guided tour in the National Congress. As a result, it was possible to verify that the leisure and tourist activities can be tools in educational development and greater social inclusion factor.

Key words: Tourism; Leisure; Down syndrome; Social inclusion; Guided tour; National Congress.

\footnotetext{
* Formação: Graduação em Turismo (Bacharelado) pela União Pioneira de Integração Social (UPIS/DF). E-mail: carolina.augusti@gmail.com

** Formação: Graduação em Turismo pela União Pioneira de Integração Social (UPIS/DF), Mestrado em Turismo e Hotelaria pela Universidade do Vale do Itajaí (UNIVALI/SC) e Doutorando em Turismo e Hotelaria (UNIVALI/SC). Atividade profissional: Professor do Instituto Federal de Educação, Ciência e Tecnologia de Brasília (IFB). Endereço físico para correspondência: Via L2 Norte, SGAN 610 (610 Norte), Módulo D, E, F e G. CEP 70.830-450 - Brasília - Distrito Federal - Brasil. E-mail: luiz.junqueira@ifb.edu.br
} 


\section{INTRODUÇÃO}

As pessoas com síndrome de Down possuem limitações físicas e psicológicas que nem sempre as impedem de desenvolver determinadas atividades, mas geram preconceitos individuais e coletivos devido à falta de conhecimento da população a respeito das necessidades e características desse grupo social (PUESCHEL, 1993; NERI, 2003).

Desse modo, entende-se que é preciso realizar pesquisas específicas a respeito do comportamento desse grupo social para que sejam demonstradas suas características pessoais, estimulando uma melhor compreensão por parte da sociedade em relação a esse grupo.

Com a finalidade de contribuir na compreensão das necessidades das pessoas com síndrome de Down, nessa pesquisa se observou o comportamento de um grupo de pessoas com síndrome de Down em um momento de usufruto de um passeio de lazer em um atrativo turístico de Brasília/DF para, de certa forma, ajudar nos estudos sobre o assunto e, consequentemente, contribuir para que os profissionais de turismo comecem a se preocupar com a inclusão social de pessoas com necessidades específicas reconhecendo os cuidados necessários para este público.

De acordo com a Declaração Universal dos Direitos Humanos, todas as pessoas têm direitos iguais, assim como direito à educação, lazer e a participar da vida cultural da sociedade (ONU, 1948). Portanto pode-se dizer que uma visita guiada pelo Senado Federal se torna uma maneira lúdica de atender aos direitos cognitivos para os deficientes.

Além de servir como uma ferramenta educacional, essa atividade é importante para uma maior integração, já que a educação é um meio para desenvolver o comportamento do ser humano no processo que é chamado de endoculturação, que é o processo permanente de aprendizagem de uma cultura que se inicia com assimilação de valores e experiências a partir do nascimento de um indivíduo e que se completa com a morte (LARAIA, 2006). Além disso, uma participação mais ativa na vida cultural permite uma maior articulação com a sociedade.

Portanto, considerou-se nesse estudo a possibilidade de identificar se a visita guiada pelo Congresso Federal poderia servir como um instrumento de formação 
educacional e cultural, além de incluir socialmente as pessoas com síndrome de Down na vida cotidiana da cidade.

Portanto, o objetivo desse trabalho foi analisar o comportamento de um grupo de pessoas com síndrome de Down em Brasília/DF, durante uma visita guiada pelo Congresso Federal com a finalidade de observar as expectativas e necessidades deste público específico no aproveitamento cultural e educativo que essa atividade poderia propiciar.

Para atingir esse objetivo foi necessário descrever as atividades oferecidas pelo passeio guiado; identificar as dificuldades e resistências por parte do espaço físico do Congresso Federal e todos os locais envolvidos no percurso; levantar com os responsáveis pelos deficientes a eficácia da visita guiada pelo Senado Federal no desenvolvimento educacional, cultural e social dos mesmos e; observar o comportamento das pessoas com síndrome de Down durante a atividade para identificar as expectativas, atitudes e curiosidades a respeito do passeio.

Como metodologia, foi realizada uma pesquisa de abordagem qualitativa, sendo construído um conhecimento empírico por meio da interação entre pesquisador e pesquisado e da realidade existente, pois segundo Dencker (1998, p. 119), esse tipo de pesquisa "exige que o pesquisador vá a campo e assuma uma atividade no grupo para poder acompanhar de perto a dinâmica do fenômeno observado". Portanto, para confirmar e aplicar esse método proposto, um dos pesquisadores participou e acompanhou o grupo durante a visita guiada.

Para análise e interpretação dos dados foi feita uma análise de conteúdo por meio das técnicas bibliográfica e documental, baseando-se nos temas a respeito dos Direitos Humanos, Inclusão Social, Declaração Universal dos Direitos Humanos, Turismo, Lazer, Síndrome de Down, Educação, Saúde, Cultura e a Constituição de 1988. Complementando, utilizou-se a técnica de levantamento para realizar as entrevistas com o público específico.

A amostra desse estudo foi um grupo de sete pessoas com síndrome de Down, sendo três mulheres e quatro homens, com idades entre 14 e 40 anos, observando-se o comportamento deles durante uma visita guiada pelo Congresso Nacional. 


\section{REVISÃO BIBLIOGRÁFICA}

Neste tópico abordou-se sobre o significado de direitos humanos, orientados pela Declaração Universal da Organização das Nações Unidas, levando-se especificamente o entendimento dos direitos das pessoas deficientes, no qual as pessoas com síndrome de Down se incluem. Foi feita, ainda, uma leitura da Constituição Federal de 1988 e a relação dos direitos sociais dos deficientes na perspectiva brasileira. Após esse panorama, realizou-se uma descrição dos marcos legais do turismo e, por fim, uma caracterização do perfil das pessoas com síndrome de Down.

\subsection{DIREITOS HUMANOS}

A expressão "Direitos Humanos" é uma forma abreviada de mencionar todos os direitos fundamentais dos seres humanos. São considerados como direitos fundamentais aqueles que as pessoas precisam para garantir a existência em sociedade, se desenvolver física, cultural e intelectualmente ou participar plenamente da vida dentro dos padrões de cada comunidade (DALLARI, 1998).

Dallari (1998) menciona que cada ser humano é um indivíduo com direitos próprios e que não é possível viver sem a companhia e o apoio de outros indivíduos com os mesmos direitos e devido a essa convivência permanente é que existem as sociedades humanas.

Portanto, acredita-se que esses direitos fundamentais devem ser iguais a todos, pois toda pessoa nasce igual em dignidade. Mas essa afirmação não significa igualdade física, intelectual ou psicológica, e sim que cada pessoa tem sua individualidade, seu modo de ver e sentir a vida, sua personalidade e deve ser respeitada por isso.

\subsubsection{Declaração Universal dos Direitos Humanos}

A Organização das Nações Unidas - ONU aprovou a Declaração Universal dos Direitos Humanos em 10 de dezembro de 1948, apresentando um conjunto de trinta artigos nos quais são indicados os Direitos Fundamentais e suas exigências (ONU, 1948). De acordo com Dallari (1998) essa declaração foi assinada por países do mundo inteiro, inclusive o Brasil, como um compromisso moral para toda a humanidade. 
Pontuando alguns tópicos da Declaração, a ONU considera que todos os homens nascem livres e iguais em dignidade e direitos. São dotados de razão e consciência e devem agir em relação uns aos outros com espírito de fraternidade. Independentes da raça, sexo ou religião, todas as pessoas são iguais e devem agir com consciência e solidariedade com o outro (ONU, 1948).

Na Declaração, a ONU (1948) considera que todo homem tem o direito de ser, em todos os lugares, reconhecido como pessoa humana, perante a lei. Toda pessoa, independente do seu nível intelectual ou capacidade física deve ser respeitada como um ser humano.

Portanto, todo homem tem o direito de participar livremente da vida cultural da comunidade, de usufruir das artes e de participar do progresso científico e de seus benefícios (DE ALMEIDA, 1996). Todo homem tem direito à proteção dos interesses morais e materiais decorrentes de qualquer produção científica, literária ou artística da qual seja autor. As pessoas vivem em sociedades e cada sociedade tem sua identidade cultural, portanto, todas as pessoas devem, por direito, ter acesso e participar das atividades culturais do grupo a que pertencem (ONU, 1948).

\subsubsection{Dados sobre Deficientes}

Os direitos fundamentais devem ser iguais a todos mesmo que existam as diferenças físicas, intelectuais ou psicológicas, conforme se pôde observar na Declaração dos Direitos Humanos. Pode-se considerar como diferença o sexo, a raça, credo e pessoas com deficiência (física e intelectual). No entanto, nenhuma dessas diferenças deve ser mais importante do que o próprio ser humano com suas necessidades fundamentais.

Costilla, Neri e Carvalho (2010) mencionam que desde os anos 2000 havia cerca de 500 milhões de pessoas com deficiência no mundo sendo que $80 \%$ delas estavam vivendo em países em desenvolvimento. Segundo esses autores, cerca de $10 \%$ da população de países em desenvolvimento era formada por pessoas com deficiência. Dessas pessoas, $50 \%$ possuindo deficiência mental; $20 \%$ deficiência física; $15 \%$ deficiência auditiva; $10 \%$ deficiência múltipla e $5 \%$ deficiência visual.

A partir desses dados percebe-se que existem muitas pessoas no mundo com deficiências, por isso, elas não podem ser ignoradas e deixadas de lado, sua participação 
na sociedade deve ser ativa em todos os aspectos. Outro fator relevante para o reconhecimento desse grupo social seria a atualização dos dados estatísticos que demonstrem esses números atualizados, pois para essa pesquisa não foram encontrados dados recentes.

\subsubsection{Declaração Universal dos Direitos das Pessoas Deficientes}

O termo "pessoas deficientes" refere-se a qualquer pessoa incapaz de assegurar por si mesma, total ou parcialmente, as necessidades de uma vida individual ou social normal, em decorrência de uma deficiência, congênita ou não, em suas capacidades físicas ou mentais (PUESCHEL, 1993). Isso não significa que elas não tenham os mesmos direitos, só não conseguem realizar algumas atividades sozinhas.

A resolução voltada para garantir os direitos das pessoas com deficiência foi aprovada pela ONU em 09 de dezembro de 1975 por meio do Comitê Social Humanitário e Cultural, com o objetivo de proteger os direitos e assegurar o bem estar e reabilitação de pessoas em desvantagem física e mental (ONU, 1975).

As pessoas deficientes gozarão de todos os diretos estabelecidos nesta Declaração. Desse modo, estes direitos serão garantidos a todas as pessoas deficientes sem nenhuma exceção e sem qualquer distinção ou discriminação com base em raça, cor, sexo, língua, religião, opiniões políticas ou outras, origem social ou nacional, estado de saúde, nascimento ou qualquer outra situação que diga respeito ao próprio deficiente ou a sua família (ONU, 1975).

As pessoas deficientes têm o direito inerente de respeito por sua dignidade humana (ONU, 1975). Qualquer que seja a origem, natureza e gravidade de suas deficiências, elas têm os mesmos direitos fundamentais que seus concidadãos da mesma idade, o que implica, antes de tudo, o direito de desfrutar de uma vida decente, tão normal e plena quanto possível (ONU, 1975). Desse modo, pode-se afirmar que as pessoas com deficiências devem ter uma vida o mais próximo da normalidade possível, pois elas são, acima de tudo, seres humanos e devem ser respeitados como tal.

Continuando a declaração, as pessoas deficientes têm direito a medidas que visem capacitá-las a tornarem-se tão autoconfiantes quanto possível (ONU, 1975). Elas devem ter oportunidades de capacitação e de medidas, como garantir sua independência, que aumente sua autoestima como pessoa. 
Por fim, as pessoas deficientes têm direito de viver com suas famílias ou com pais adotivos e de participar de todas as atividades sociais, criativas e recreativas (ONU, 1975). Nenhuma pessoa deficiente será submetida, em sua residência, a tratamento diferencial, além daquele requerido por sua condição ou necessidade de recuperação (ONU, 1975).

Segundo a ONU (1975), se a permanência de uma pessoa deficiente em um estabelecimento especializado for indispensável, o ambiente e as condições de vida nesse lugar devem ser, tanto quanto possível, próximos da vida normal de pessoas de sua idade. Percebe-se que a base familiar é importante para todas as pessoas e para os deficientes não deve ser diferente. Participar desse convívio é fundamental para um bom desenvolvimento e suas diferenças devem ser respeitadas.

\subsection{A CONSTITUIÇÃO DE 1988 E OS DEFICIENTES}

$\mathrm{Na}$ Constituição Brasileira de 1988 houve grandes conquistas para os deficientes. Uma dessas conquistas é o Decreto Federal 914 de 1993, que institui a Política Nacional para a integração da pessoa com deficiência e que tem como artigos importantes o Art. $1^{\circ}$ em que consta que a Política Nacional para a Integração da Pessoa Portadora de Deficiência é o conjunto de orientações normativas, que objetivam assegurar o pleno exercício dos direitos individuais e sociais das pessoas portadoras de deficiência (BRASIL, 1988).

Já o Decreto Federal 5.296 de 2004 permitiu que pessoas com deficiências e mobilidade reduzida passassem a ter o direito de fazer turismo como mais um meio de integração social, pois regulamenta a lei $n^{\circ}$. 10.048, de 8 de novembro de 2000 , que garante prioridade de atendimento às pessoas que especifica, e a lei $\mathrm{n}^{\circ} .10 .098$, de 19 de dezembro de 2000, que estabelece normas gerais e critérios básicos para a promoção da acessibilidade das pessoas portadoras de deficiência ou com mobilidade reduzida.

\subsubsection{Marcos Legais no Turismo}

No turismo também houve alguns marcos legais que ajudaram o país a desenvolver uma maior integração dos deficientes na sociedade. O Ministério do Turismo (2009), por exemplo, elaborou o Plano Nacional do Turismo 2007/2010 - Uma 
Viagem de Inclusão, que tem como objetivo fazer do turismo um indutor da inclusão social tanto com a criação de novos postos de trabalho quanto pelo consumo, com a absorção de novos turistas.

Neste contexto, pretendendo-se gerar incremento de renda e emprego nos destinos e ampliar o acesso das diferentes camadas da população ao turismo, o que inclui a acessibilidade às pessoas com deficiência e mobilidade reduzida, sendo os requisitos centrais do que vêm sendo observados na estruturação de políticas para o Turismo Social (BOULLON, 2004; CASTRO, 2002).

\subsection{SÍNDROME DE DOWN}

Segundo Werneck (1993, p. 60) "síndrome quer dizer conjunto de sinais e de sintomas que caracterizam um determinado quadro clínico. No caso da síndrome de Down, um dos sintomas é a deficiência mental". Ou seja, a pessoa com síndrome de Down tem deficiência mental (que varia em níveis diferentes), mas isso não é exclusivo, a síndrome de Down, na verdade, é um conjunto de vários sintomas e características físicas que a define.

A história da síndrome de Down no mundo começa no século XIX, antes os deficientes intelectuais eram vistos como um grupo homogêneo. Em 1866, o cientista inglês John Langdon Down fez uma observação interessante, ele questionou por que algumas crianças, mesmo filhas de europeus, eram parecidas entre si e tinham traços que lembravam ao povo mongol, principalmente pela inclinação das pálpebras, similar aos dos asiáticos (WERNECK, 1993).

A descrição feita pelo pesquisador sobre a população estudada foi: “o cabelo não é preto, como acontece com o povo mongol, mas sim de uma cor amarronzada, além de serem ralos e lisos. A face é achatada e larga. Os olhos são oblíquos e o nariz é pequeno. Estas crianças têm uma capacidade grande de imitar" (WERNECK, 1993).

Para Pueschel (1993) as pessoas com síndrome de Down possuem características físicas particulares, formadas pela influência do material genético. Segundo o autor, essas características tem-se a cabeça um pouco menor com a parte posterior achatada, nariz pequeno, pálpebras estreitas e levemente oblíquas, a boca pequena e língua com estrias. No entanto, o autor afirma que nem todas as pessoas com síndrome de Down possuem todas essas características, algumas são mais acentuadas do que outras. 
Nem toda doença tem cura e a natureza mantém vivo aqueles que são considerados perfeitos do ponto de vista genético, os que sofrem de alguma alteração genética acabam tendo doenças provocadas por essas alterações o que diminui a expectativa de vida deles (WERNECK, 1993).

De acordo com uma reportagem da Revista do Correio Brasiliense de 11 de maio de 2012, novos exames, medicamentos, diagnósticos precoces e acesso a informações têm garantido uma vida mais longa e melhor aos portadores de algumas doenças genéticas complicadas ou raras.

Segundo Mustacchi, responsável pelos cursos de especialização em Síndrome de Down em São Paulo e Brasília, em reportagem ao Correio Braziliense (2012), a partir dos anos 2000 a expectativa de vida das pessoas com síndrome de Down passa a ser de 70 anos e muitos deles chegam à velhice. Para ele, isso ocorre "graças aos programas de atenção à saúde, de imunização, de prevenção e de nutrição".

Por sua vez, para Dallari (1998, p. 47), a educação é um processo de aprendizagem e aperfeiçoamento que:

[...] as pessoas se preparam para a vida. Através da educação obtém-se o desenvolvimento individual da pessoa, que aprende a utilizar do modo mais conveniente sua inteligência e sua memória. Desse modo, cada ser humano pode receber conhecimentos obtidos por outros seres humanos e trabalhar para a obtenção de novos conhecimentos. Além disso, a educação torna possível a associação da razão com os sentimentos, propiciando o aperfeiçoamento espiritual das pessoas.

Assim, de acordo com Dallari (1998), a educação é importante na vida de todos os seres humanos. Pode-se dizer que a educação torna as pessoas preparadas para a vida e para a convivência. Portanto, a pessoa educada tem mais facilidade para compreender os demais, para aceitar as diferenças que existem de um indivíduo para o outro e para dar apoio ao desenvolvimento interior e social das outras pessoas.

A educação é um direito de todos, conforme a Declaração Universal dos Direitos Humanos (1948) é uma ferramenta fundamental para o desenvolvimento individual da pessoa e para uma melhora no convívio em sociedade. As pessoas com deficiência, apesar de terem suas limitações, também necessitam de uma educação e a Declaração de Salamanca defende esse direito (UNESCO, 1994). Ela defende uma escola inclusiva, que se adapte às diferenças de cada aluno, mas também defende o direito à educação e 
cultura acima de qualquer coisa e que as pessoas com deficiência e os pais possam participar ativamente do planejamento das atividades educacionais.

Entende-se como cultura "todo este complexo que inclui conhecimentos, crenças, arte, moral, leis, costumes ou qualquer outra capacidade ou hábitos adquiridos pelo homem como membro de uma sociedade." (LARAIA, 2006, p. 25).

Para Laraia (2006) a endoculturação, é o processo permanente de aprendizagem de uma cultura que se inicia com assimilação de valores e experiências a partir do nascimento de um indivíduo e que se completa com a morte. Por isso é importante a participação da pessoa com síndrome de Down na vida cultural a fim de permitir seu desenvolvimento, sua socialização e uma maior articulação com os demais membros da sociedade.

Neri (2003) menciona que a necessidade de inclusão social é um sinal de que existem grupos excluídos, ou seja, pessoas que não têm acesso aos direitos que lhes pertencem como acesso à educação, saúde, transporte, esporte, cultura e lazer. Segundo o autor, mesmo existindo leis que os garantam, as pessoas consideradas diferentes são excluídas por meio de ações sociais que impedem o desenvolvimento do universo de direitos e deveres desses cidadãos. Dentre os indivíduos excluídos, destacam-se os deficientes físicos e mentais.

O grande desafio da sociedade é enxergá-los como seres humanos e iguais e não apenas como portadores de uma limitação que, às vezes, pode diminuir mediante uma ação social (NERI, 2003). Essas ações sociais podem existir em diversos setores da sociedade como educação, legislação, meio ambiente, educação, trabalho, lazer e cultura entre outros.

O Programa de Ação Mundial para as Pessoas com Deficiência (1982) propõe algumas ações para inclusão social em diversos setores. Entre os setores tem-se o lazer que sugere que deve fazer com que as pessoas portadoras de deficiência tenham as mesmas oportunidades dos demais cidadãos para participarem de atividades de lazer (VIEIRA, 2006).

Isso supõe a possibilidade de utilizar restaurantes, cinemas, teatros, bibliotecas etc., bem como locais de férias, estádios, hotéis, praias e outros locais de lazer. As autoridades do setor turístico, as agências de viagens, os hotéis, as organizações voluntárias e outras entidades envolvidas na organização de atividades de lazer ou de 
oportunidades de viagem, devem oferecer os seus serviços a todos, sem discriminar as pessoas portadoras de deficiência. Isso implica, por exemplo, a inclusão de informações sobre acessibilidade na informação habitual que oferecem ao público (VIEIRA, 2006).

Deve-se procurar fazer com que as pessoas portadoras de deficiência tenham a oportunidade de utilizar ao máximo as suas capacidades criadoras, artísticas e intelectuais, não apenas em seu próprio benefício como também, para o enriquecimento da comunidade (VIEIRA, 2006).

Desse modo, com este objetivo, deve-se assegurar o seu acesso às atividades culturais. Se necessário, devem-se realizar adaptações especiais para atender às necessidades das pessoas portadoras de deficiência mental ou sensorial. A esfera das atividades culturais, para Vieira (2006) compreende a dança, a música, a literatura, o teatro e as artes plásticas.

Já as atividades recreativas, segundo Pueschel (1993, p. 227), “podem ser reconhecidas como um importante meio de aprendizagem e um elemento chave no desenvolvimento das pessoas com síndrome de Down." Pois a educação é uma ferramenta fundamental no desenvolvimento comportamental de todo ser humano, toda pessoa é um ser cultural e até atividades recreativas podem ajudar nesse desenvolvimento.

Pueschel (1993, p. 228) completa afirmando que por meio da participação em atividades recreativas é possível obter vários benefícios como:

Senso de realização, consciência corporal, desafios físicos e mentais, melhoria da autoestima, participação na comunidade, oportunidade de competir, expressão criativa, chance de fazer amizades, exercício, sensação de pertencer a um grupo, oportunidade de encontrar novos talentos, melhoria nas habilidades esportivas, desenvolvimento da coordenação, meio de extravasar emoções, relaxamento, desenvolvimento de habilidades sociais, e diversão.

O incentivo à acessibilidade no turismo é importante para promover a integração das pessoas com deficiências com a sociedade, "o turismo focado no estímulo ao consumo de lazer para camadas sociais menos beneficiadas ao mesmo tempo em que inclui as comunidades aonde ele se envolve, vem sendo considerado uma das melhores estratégias para inclusão social.” (MINISTERIO DO TURISMO, 2009, p. 10).

Nesta conjuntura, é imprescindível criar condições adequadas de estímulo e acessibilidade, respeitando a todos e objetivando a inclusão das pessoas com 
deficiência, não só na atividade turística, mas em todo âmbito social (BIZINELLI et al., 2014).

Acredita-se que a inclusão social acontece quando a sociedade modifica seu sistema de lazer e turismo para que todas as pessoas possam participar juntas e desfrutar de momentos de lazer em ambientes comuns. Para tanto, o Ministério do Turismo (2009) defende que o turismo pode provocar uma satisfação pessoal, seja viajando ou realizando uma atividade de lazer, pois são fatores que provocam sensações importantes nas pessoas.

\section{APRESENTAÇÃO E ANÁLISE DOS RESULTADOS}

A partir da entrevista semiestruturada realizada com o coordenador de educação inclusiva do Distrito Federal para identificar as políticas sociais voltadas para pessoas com deficiência teve-se como resposta a informação de que o governo local estava fazendo um trabalho na área social que visava romper barreiras e melhorar o trânsito das pessoas com deficiência em qualquer situação.

De acordo com o entrevistado, foi criada a comissão da defesa da pessoa com deficiência da Ordem dos Advogados - OAB atuando no sentido de fazer com que se conseguisse a defesa da pessoa com deficiência no Distrito Federal com o apoio do Ministério Público.

Complementando a entrevista, o entrevistado afirmou que na prática "o pessoal com deficiência só tinha dificuldade de superação e essas dificuldades só são superadas na medida em que o Estado provém essas pessoas no sistema de aditivos, tecnológicos, materiais, profissionais mais especializados”. Então segundo ele, na prática não é a mesma coisa, porque incluir alguém que está em risco e que coloca a sociedade em risco é diferente de incluir uma pessoa com deficiência que, a não ser que ela esteja em situação de risco, e a grande maioria não está em situação de risco nem colocam a sociedade em risco, pelo contrário, estão em desvantagem no sistema como um todo.

Para o entrevistado, o Ministério da Educação - MEC estava tentando adequar as escolas no país inteiro com acessibilidade de um modo geral, com implantação de salas com recursos tecnológicos e assim por diante. Para o entrevistado "os professores 
estavam tendo, na medida do possível, curso de formação continuada". Segundo ele "a grande questão era a boa vontade, o amor, e a quebra do preconceito, se isso acontecesse tudo ficaria mais fácil”.

O Brasil é o país que mais tem leis no que diz respeito a pessoas com deficiências ultimamente, existindo o Programa Sem Limite (2011) do Governo Federal que está sendo distribuído pelos estados para que ocorra a valorização de afirmativas, no sentido da inclusão social, da educação e de várias outras áreas da sociedade, segundo o entrevistado.

Para o entrevistado, seria necessário fazer o trabalho de base, teria que pegar todas as crianças que nascem e são identificadas como tal e realizar um serviço especializado, para fazer com que essas crianças, por exemplo, tenham o mínimo de deficiência intelectual e isso requereria realmente um serviço muito específico de estímulo, de todas as áreas como cognitivas, motoras, afetivas e assim por diante.

O entrevistado disse, ainda, que as práticas pedagógicas "deveriam incentivar o desenvolvimento intelectual, afetivo, coordenação motora e de convivência, porque na prática as pessoas têm uma dificuldade de exigir, de enquadrar a pessoa com deficiência dentro da sociedade".

Espera-se que, segundo o entrevistado, na medida em que essas pessoas com síndrome de Down são colocadas numa posição de conhecimento, de estar em contato com o conhecimento, estar em contato com a sociedade, sujeitos de suas próprias ações, estarem sendo estimuladas a agirem, como por exemplo, a dançarem, a pintar quadros, enfim, a fazer tudo quanto é tipo de atividade necessária para que eles se sintam bem, automaticamente a expectativa de vida aumenta.

Para tanto, o turismo, de acordo com o entrevistado, ampliava bastante o horizonte dessas pessoas, dando um estímulo muito grande, para que elas conhecessem todos os pontos turísticos da sociedade em que estavam vivendo, conhecessem pessoas, novos espaços, enfim, é um conhecimento que estimulava o indivíduo a se sentir incluído. O entrevistado complementa ao afirmar que as pessoas se esquecem de que isso é uma via de mão dupla, na medida em que empodera, aumenta a responsabilidade. O entrevistado afirmou, ainda, que isso seria interessante porque essas pessoas poderiam, a partir daí, ter oportunidade, de repente, de trabalhar. 
Por fim, o entrevistado disse que quando se falava de inclusão social era tão amplo quanto o assunto acessibilidade. Para o entrevistado, "em primeiro lugar a acessibilidade não é inclusão, quando se fala em acessibilidade se fala do acesso ao pão de cada dia, à saúde, ao transporte, à segurança, à casa própria, à educação, ao lazer, ao turismo" (que é lazer, mas é uma proposta educativa muito importante).

Segundo ele, "inclusão social é a inserção efetiva de pessoas na sociedade, onde essas pessoas têm o empoderamento para participar e influenciar as decisões, compartilhando as tarefas e assim por diante".

De acordo com o entrevistado, para melhorar a educação de pessoas com síndrome de Down dever-se-ia fazer um trabalho de base com elas, ou seja, desde o momento do nascimento já seria preciso um acompanhamento e estímulos que as ajudassem a desenvolver ao máximo suas capacidades, além das práticas pedagógicas que incentivassem o desenvolvimento pessoal.

Em outra perspectiva da pesquisa, identificou-se o Senado Federal que estava realizando em parceria com a Câmara dos Deputados, um programa de visitas guiadas ao Palácio do Congresso Nacional. As visitas aconteciam todos os dias, inclusive sábados, domingos e feriados, das $09 \mathrm{~h} 30$ às $17 \mathrm{~h}$, com saídas de grupos a cada meia hora. As visitas eram gratuitas, e os grupos eram conduzidos por uma equipe de monitores das duas Casas legislativas e percorriam um roteiro que mostra os principais pontos do Congresso. Grupo com necessidades especiais deveriam agendar com antecedência.

Existiam dois tipos de roteiro no Congresso Nacional, um para adultos e outro infanto-juvenil. O roteiro para pessoas com síndrome de Down foi adaptado do roteiro infanto-juvenil. Esse roteiro ainda estava em fase de testes no momento da pesquisa sendo a segunda vez que se realizou esse guiamento específico.

De acordo com informações colhidas com os próprios monitores, eles informaram que não precisaram de cursos específicos, mas quando começaram a trabalhar no Congresso, receberam treinamentos para saber o roteiro, a história, como era feito o processo de leis e como passar essas informações para os visitantes.

No caso do roteiro para síndrome de Down, segundo os monitores, além desse treinamento, também estudaram sobre a síndrome (a causa, características, como foi descoberta) e foram treinados para ter uma linguagem mais interativa e simples. 
As principais diferenças para um guiamento padrão e esse específico, além do treinamento diferenciado dos monitores, são: a linguagem mais simples, com exemplos do cotidiano do grupo; a duração é mais curta; menor quantidade de conteúdo explicado e o grupo é acompanhado por três guias, para poder dar atenção a todos e auxiliar no deslocamento pelo Congresso (ONU, 1982).

Percebeu-se na observação da pesquisa que a linguagem utilizada na visita foi satisfatória, bem didática e simples, os jovens não se dispersaram e prestaram atenção na maior parte do tempo. A monitora foi atenciosa e vários pais elogiaram a linguagem usada e a interação que teve com os jovens, ela explicava e fazia perguntas sobre o que falou e eles souberam responder corretamente. Houve uma grande interatividade e a monitora realmente soube manter o grupo interessado.

Os jovens se comportaram muito bem, atenderam todas as regras explicadas pela monitora no começo, agiram com educação e sempre interessados no que era passado, alguns jovens levaram máquinas para tirar fotos e outro um bloco onde anotava tudo que era falado porque queria contar depois sobre o passeio para os colegas. Quando a monitora explicava alguma coisa, eles comentavam, achavam legal e repetiam o que era falado. Os pais também estavam interessados e faziam perguntas, houve muita interação entre pais e filhos, se preocupavam se os filhos estavam entendendo e pediam atenção, explicavam de novo o que era falado.

Quando o grupo estava no Plenário da Câmara, os jovens gostaram da ideia de "serem deputados" e alguns comentaram que queriam ser deputados. No Salão Verde gostaram muito das maquetes, pois tiveram uma interação maior, podiam tocar.

O passeio foi feito especialmente com o grupo, não tendo muito contato com pessoas que faziam o guiamento padrão, mas no Salão Verde os grupos se encontraram apesar de não haver interação o outro grupo não teve nenhuma reação preconceituosa e olharam com curiosidade e respeito.

No final os jovens se mostraram felizes com o passeio, e comentavam o que tinham visto. Os pais gostaram muito e acharam as monitoras muito interativas e atenciosas, elas foram muito carinhosas com o grupo, não demonstrando estranhamento ou incômodo em nenhuma situação, pelo contrário, estavam bem à vontade com os jovens (o que foi muito elogiado pelos pais: a postura das monitoras). 
Portanto, baseado nessa pesquisa, acredita-se que o passeio pôde ajudar no desenvolvimento educacional, os jovens se mostraram atentos, repetiam o que ouviam e assimilaram as informações passadas com o conhecimento que já obtinham, no final do passeio estavam bem animados e fizeram comentários sobre tudo o que foi ensinado.

Na questão da inclusão social, apesar dos jovens não terem contato direto com os outros grupos que visitavam o Congresso, as guias foram atenciosas, não houve nenhum comportamento que pudesse ser considerado como exclusivo, e eles estavam ali sendo vistos pelas pessoas que passavam por eles.

Os entrevistados portadores de síndrome de Down disseram que gostavam de visitar lugares culturais da cidade (biblioteca, teatro, museu, entre outros) e ficar em casa com a família. Também que gostavam de frequentar parques, dançar e praticar esportes, ou seja, os jovens gostavam de passeios culturais, não gostavam de ficar em casa, gostavam de atividades que ajudassem no desenvolvimento intelectual, além do lazer.

Quando questionados se "gostavam de fazer novas amizades e conhecer pessoas diferentes" a maioria respondeu sim, que sempre procuravam fazer novas amizades e tinham facilidade, somente duas pessoas colocaram que faziam amizade com conhecidos de conhecidos e familiares, portanto deveriam existir projetos que os colocassem em contato com outras pessoas, pois gostavam dessa interação.

Perguntou-se, ainda, "quem decidia seus passeios". Como resposta, teve-se que escolhiam junto com os pais, que os pais decidiam e, também, responderam que escolhiam sozinhos os passeios que queriam fazer, ou seja, na maioria das vezes a opinião sobre os locais visitados partia dos jovens, e, como foi visto, gostavam de lugares culturais o que mostrava a vontade de conhecer coisas novas.

Os jovens com síndrome de Down conheciam praticamente todos os espaços de lazer e atrativos turísticos de Brasília, os que não conheciam todos, já haviam passeado pelo menos por uns três locais diferentes, por isso seria importante que todos os atrativos turísticos estivessem preparados para receber esse grupo.

De acordo com as entrevistas realizadas, percebeu-se que eles gostavam de estudar em sala de aula na escola porque os professores e colegas ajudavam. No entanto, somente um respondeu que preferia estudar fora da sala de aula, pois tinha dificuldade de aprender, gostavam de estudar em sala a partir do momento em que eram 
incentivados, portanto, se são incentivados ao conhecimento mostram dedicação e vontade.

Ao questionar "o que você achou do passeio do Congresso" todos, sem exceção, responderam que acharam o passeio educativo e divertido, gostavam de conhecer coisas novas e que gostavam de cultura. Todos responderam também, sem exceção, que gostariam de mais passeios como esse e inclusive foi sugerido um piquenique. Portanto o turismo poderia, facilmente, ajudar no desenvolvimento educacional, pois além de se divertirem, eles também aprendem.

A última questão foi aberta e perguntava sobre o que mais a pessoa gostou no passeio do Congresso Federal e as respostas foram: gostou de aprender coisas novas, gostaram de conhecer os salões, de ver a bola que o Neymar (jogador de futebol) deu de presente para o presidente da Câmara, gostaram da brincadeira de serem deputados e principalmente de estarem todos juntos e de estarem com os colegas.

Portanto, percebeu-se que eles gostaram do contato com pessoas diferentes, o que deve ser incentivado com atividades onde haja interação. Os jovens demonstraram serem abertos ao conhecimento e realmente acharam aprender divertido, desde que sejam incentivados. A visita do Congresso Nacional mostrou, através do questionário, que o turismo poderia ser uma ferramenta educacional e de inclusão social, desde que os atrativos estejam preparados para recebê-los.

Quando questionou os pais e responsáveis a respeito da visita no Congresso todos, sem exceção, acharam o Congresso (lugares por onde passa a visita guiada) acessível e inclusivo para pessoas com síndrome de Down e completaram escrevendo que o Congresso atendeu a legislação e os aspectos da cidadania, deu oportunidade para os jovens conhecerem mais e gostaram muito das monitoras que guiaram o passeio, acharam elas didáticas, com boa vontade e disposição, o que é importante pois pela lei todo atrativo deveria ser acessível, significando que o Congresso é um local seguro e acessível para que esse grupo possa visitá-lo sempre que quiser sem a preocupação de ser seguro ou não.

Foi perguntado aos pais e responsáveis, se concordavam que "houve um aumento da preocupação da sociedade em incluir as pessoas com síndrome de Down na vida cultural" e 4 pessoas responderam que concordavam plenamente, 2 pessoas responderam que poucas pessoas se preocupavam com esse público e 1 pessoa 
respondeu que não concordava, apesar de não ser unanimidade, a maioria mencionou acreditar que houve uma maior preocupação da sociedade em incluir pessoas com Down, o que significaria que eles estavam sendo mais aceitos e portanto deveriam ter seu espaço reservado na sociedade e suas diferenças respeitadas.

Por último, foi pedido para a pessoa fazer algum comentário a respeito do comportamento do seu filho/a em relação à inclusão social e as respostas foram: "as atividades sociais têm favorecido muito o desenvolvimento do meu filho"; "é preciso promover a inclusão em todos os aspectos sociais"; "atividades como este passeio são um estímulo cognitivo e físico, muito bom para o desenvolvimento das pessoas com síndrome de Down e para a inclusão social"; "a inclusão ainda está longe de ser satisfatória"; "o meu filho é fácil de integrar socialmente, já trabalhava e estudava e gostava de dançar e cantar"; "a inclusão poderia ser melhor e mais fácil para quem não tem condições de oferecer lazer a altura das pessoas com síndrome de Down".

Percebeu-se a importância que os pais viam nas atividades sociais como um meio de desenvolvimento, e que passeios como esse poderiam ajudar, ainda que existissem muitas barreiras a serem derrubadas, mas o turismo, definitivamente, poderia ser bem mais do que uma atividade de lazer, podendo melhorar ainda mais na inclusão desse grupo diferenciado.

\section{CONSIDERAÇÕES FINAIS}

Nessa pesquisa se analisou o comportamento de um grupo de 7 (sete) pessoas com síndrome de Down durante uma visita a um atrativo turístico (Congresso Nacional) para saber qual o aproveitamento cultural e educativo que essa atividade poderia propiciar. No final dessa visita guiada foram realizadas entrevistas com os pais e responsáveis das pessoas com síndrome de Down, assim como entrevistas com os próprios. Realizou-se, ainda, uma entrevista com o coordenador de Educação Inclusiva no Distrito Federal.

Todas as atividades realizadas durante a visita guiada foram anotadas e registradas para posterior análise do comportamento das pessoas com síndrome de 
Down. Como resultado percebeu-se que eles se comportaram como qualquer pessoa interessada em aprender e conhecer um novo lugar visitado.

A única dificuldade observada foi a necessidade de um maior tempo para que as pessoas com síndrome de Down pudessem observar e absorver as informações transmitidas. $\mathrm{O}$ espaço visitado no geral estava adequado para o recebimento de pessoas com necessidades específicas. No entanto, seria preciso uma melhor qualificação do serviço educacional oferecido para que houvesse realmente um aprendizado significativo da importância do local visitado para o país.

Concluiu-se que, para essa pesquisa, esse grupo específico, atividades pedagógicas apropriando-se de elementos do turismo, são muito importantes para o aumento da qualidade de vida das pessoas com síndrome de Down, pois têm uma grande relação com o aumento do desenvolvimento educacional.

Quando as pessoas com síndrome de Down fazem atividades em que se sintam bem e têm oportunidades sociais eles se sentem incluídos socialmente, conforme foi observado na visita guiada. Além disso, segundo os documentos levantados para essa pesquisa a educação pode tornar as pessoas preparadas para a vida e para a convivência.

Percebeu-se que as pessoas com síndrome de Down demonstraram gostar do contato com pessoas diferentes, o que deve ser incentivado com atividades onde haja interação. Os jovens demonstraram serem abertos ao conhecimento e realmente acharam aprender divertido, desde que fossem incentivados.

A visita do Congresso Nacional mostrou que o turismo poderia ser uma ferramenta educacional e de inclusão social, desde que os atrativos estejam preparados para recebê-los, esse planejamento é fundamental para que pessoas com síndrome de Down possam integrar-se da melhor maneira possível e garantir o exercício pleno de sua cidadania.

É preciso mais atividades pedagógicas que ajudem as pessoas com síndrome de Down a se desenvolverem e ocupar esse tempo de vida que eles têm maior. Ainda existem muitas barreiras a serem derrubadas, mas o turismo, definitivamente, poderia ser bem mais do que uma atividade de lazer, podendo melhorar ainda mais na inclusão desse grupo diferenciado e gerar qualidade de vida. 


\section{REFERÊNCIAS}

BIZINELlI, C.; MANOSSO, F.; GIMENES-MINASSE, M. H. S.; SOUZA, S. R. Enoturismo e Turismo de Experiência: novas possibilidades para a inclusão de pessoas com deficiência visual - Vinícola Dezem (Toledo, Paraná, Brasil). Turismo \& Sociedade. Curitiba, v. 7, n. 3, p. 495-522, julho, 2014.

BOULLÓN, R. C. Atividades Turísticas e Recreativas: o Homem como Protagonista. Bauru: EDUSC, 2004.

BRASIL. Constituição: República Federativa do Brasil. - Brasília: Senado Federal, Centro Gráfico, 1988.

BRASIL. Decreto Federal n. 914 de 6 de setembro de 1993. Institui a política nacional para a integração da pessoa portadora de deficiência, e dá outras providências. Diário Oficial da União. Brasília, DF, 6/9/1993.

BRASIL. Decreto n. 5.296, de 2 de dezembro de 2004. Regulamenta as Leis números 10.148, de 8 de novembro de 2000, que dá prioridade de atendimento às pessoas que especifica, e 10.098, de 19 de dezembro de 2000, que estabelece normas gerais e critérios básicos para a promoção da acessibilidade das pessoas portadoras de deficiência ou com mobilidade reduzida, e dá outras providências. Diário Oficial da União. Brasília, DF, 3/12/2004.

BRASIL. Decreto n. 7.612 de 17 de novembro de 2011. Plano Nacional dos Direitos da Pessoa com Deficiência - Viver sem Limite. Implementa novas iniciativas e intensifica ações em benefício das pessoas com deficiência. Diário Oficial da União. Brasília, DF. 17/11/2011.

CASTRO, C. A. P. Sociologia Aplicada ao Turismo. São Paulo: Atlas, 2002.

CENTRO REGIONAL DE INFORMAÇÃO DAS NAÇÕES UNIDAS - UNRIC. Alguns factos e números sobre as pessoas com deficiência. Disponível em: $<$ https://www.unric.org/pt/pessoas-com-deficiencia/5459>. Acesso em: 11/03/2012.

COSTIlla, H. G.; NerI, M. C.; CARVAlHO, A. P. Política de cotas e inclusão trabalhista das pessoas com deficiência. Rio de Janeiro. FGV / EPGE. Novembro, 2010.

CORREIO BRASILIENSE. Revista do Correio. 11 de maio, 2012.

DALlARI, D. A. Direitos Humanos e Cidadania. São Paulo: Moderna, Coleção Polêmica, 1998.

DE ALMEIDA, F. B. Teoria Geral dos Direitos Humanos. Sergio Antonio Fabris Editor, 1996. 
DENCKER, A. F. M. Pesquisa em Turismo: Planejamento, Métodos e Técnicas. 9. ed. São Paulo: Futura, 1998.

LARAIA, R. B. Cultura: Um Conceito Antropológico. 20. ed. Rio de Janeiro: Jorge Zahar, Coleção Antropologia Social, 2006.

MINISTÉRIO DO TURISMO. Turismo Acessível: Introdução a uma Viagem de Inclusão. Volume I. Brasília, 2009.

NERI, M. Retratos da Deficiência no Brasil. Rio de Janeiro: FGV/IBRE, 2003.

$\begin{array}{lcccc}\text { ORGANIZAÇÃO DAS NAÇÕES } & \text { UNIDAS - ONU. Declaração Universal dos } \\ \text { Direitos } & \text { Humanos, } & 1948 . & \text { Disponível } & \text { em: }\end{array}$
<http://www.direitoshumanos.usp.br/index.php/Declaração-Universal-dos-DireitosHumanos/declaracao-universal-dos-direitos-humanos.html>. Acesso em: 13/04/2012.

Declaração dos Direitos das Pessoas Deficientes, 1975. Disponível em: <http://portal.mec.gov.br/seesp/arquivos/pdf/dec_def.pdf>. Acesso em: 13/04/2012.

Programa de Ação Mundial para Pessoas com Deficiências, 1982. Disponível em: <http://www.direitoshumanos.usp.br/index.php/Direito-dos-Portadoresde-Deficiêcia/programa-de-acao-mundial-para-as-pessoas-deficientes.html>. Acesso em: 08/05/2012.

PUESCHEL, S. M. Síndrome de Down: Guia para Pais e Educadores. Campinas: Papirus, 1993.

UNESCO. Declaração de Salamanca. Conferência Mundial de Educação Especial em cooperação da UNESCO. Espanha, 1994.

VIEIRA, L. C. A Comunidade, a Cultura e o Turismo. Fortaleza: Premius, série Natureza e Cultura, 2006.

WERNECK, C. Muito prazer, eu existo: um livro sobre as pessoas com síndrome de Down. Rio de Janeiro: WVA, 2. ed., 1993.

Recebido em: 14-09-2016.

Aprovado em: 14-10-2016. 